\title{
Analysis of Shrinkage on Thick Plate Part using Genetic Algorithm
}

\author{
S.N. Najihah ${ }^{1,}$, Z. Shayfull ${ }^{1,2, *}$, S.M. Nasir ${ }^{1,2,3}$, Mohd Sazli Saad ${ }^{1,2}$, M.M. Rashidi ${ }^{4}, M$. \\ Fathullah $^{1,2}$ and N.Z. Noriman ${ }^{5}$ \\ ${ }^{1}$ School of Manufacturing Engineering, Universiti Malaysia Perlis, Kampus Tetap Pauh Putra, 02600 \\ Arau, Perlis, Malaysia. \\ ${ }^{2}$ Green Design and Manufacture Research Group, Center of Excellence Geopolymer and Green \\ Technology (CEGeoGTech), Universiti Malaysia Perlis, 01000 Kangar, Perlis, Malaysia. \\ ${ }^{3}$ Centre For Diploma Studies, Universiti Malaysia Perlis, Malaysia. \\ ${ }^{4}$ Faculty of Mechanical Engineering, Universiti Malaysia Pahang, 26600 Pekan, Pahang, Malaysia. \\ ${ }^{5}$ Center of Excellence Geopolymer and Green Technology (CEGeoGTech), Faculty of Engineering \\ Technology (FETech), Universiti Malaysia Perlis (UniMAP), Level 1 Block S2, UniCITI Alam
}

\begin{abstract}
Injection moulding is the most widely used processes in manufacturing plastic products. Since the quality of injection improves plastic parts are mostly influenced by process conditions, the method to determine the optimum process conditions becomes the key to improving the part quality. This paper presents a systematic methodology to analyse the shrinkage of the thick plate part during the injection moulding process. Genetic Algorithm (GA) method was proposed to optimise the process parameters that would result in optimal solutions of optimisation goals. Using the GA, the shrinkage of the thick plate part was improved by $39.1 \%$ in parallel direction and $17.21 \%$ in the normal direction of melt flow.
\end{abstract}

\section{Introduction}

Injection moulding categorised as one of the most manufacturing process that used for producing plastic products. Differ from other, forming process, injection moulding products as well as the materials are significantly affected by the moulds quality [1]. Today, injection moulding product serves range from children's toys to automobile accessories. The process of injection moulding produces a variety of thermoplastic product with tight tolerance, high production volume and complex dimension [2]. There are many different ways of moulding such as blow moulding, injection moulding, rotational moulding and compression moulding. Each method has their benefits in the manufacturing of specific item [3].

There is a common coincidence of defects arise in injection moulding from the imperfection in mould design and inappropriate of material compound. Product quality will be lower caused by inappropriate clamping force, mould seal clearance and melting temperature along with nonuniform setting. In addition, inappropriate mass to mass ratio of

\footnotetext{
*Corresponding author: shayfull@unimap.edu.my
} 
low grade polymer is a non-conformance in the production of quality product. The most common injection moulding defects are warpage and shrinkage [4].

The webpage is one of the significant factors that affecting product quality, especially to some product that developed with thin, short, light and small design concept. Warpage become important to improve the quality of that particular design concept. Warpage is caused by uneven shrinkage of plastic parts [5]. Meanwhile, shrinkage in the mould happens is caused by thermal changes of the plastics while it is in the mould. The part can be rejected due to too much or too little shrinkage. In fact, uneven shrinkage result warpage to the moulded part. The nonuniform shrinkage gives bending or twisting out the shape, not just its dimensions, but also the angles and contour [6]. In order to avoid the shrinkage phenomenon in moulded parts, many previous researchers use parameter optimisation method. Optimisation method help to analysed the injection moulded problem and initiated various solutions [7-8]. One of the optimisation methods that widely used is a Genetic Algorithm (GA) [9].

Ozcelik and Erzurumlu [10] investigated the efficient warpage reduction on thin shell plastic parts using Finite Element (FE) analysis, statistical Design of Experiment (DOE) method, RSM and GA. A thin shell plastic part was moulded by ABS material. The FE analyses were simulated for combination of process parameters organised based on statistical full factorial experimental design. The $\mathrm{X}, \mathrm{Y}$ and $\mathrm{Z}$ dimension are considered as process conditions dimensional parameters influencing warpage. The mould temperature, melt temperature, injection time and injection pressure were taken as constant that effecting minimum warpage. The RSM was used to create a predictive model for warpage in terms of the critical process parameters. Then, the RSM model was coupled GA in order to find the optimum process parameter values. The maximum warpage on the model was $0.0977 \mathrm{~mm}$ and after optimisation the warpage was reduced to $0.0582 \mathrm{~mm}$ by $40.4 \%$ when a maximum webpage was considered.

Ozcelik and Erzurumlu [11] studied for reducing the warpage of thin shell plastic parts using the ANOVA, ANN and GA. At first, a model of PC button for the washing machine was meshed with MoldFlow software for plastic flow analysis. Then, Taguchi method was applied for identifying the significant processing parameters which are the melt temperature, mould temperature, packing time, packing pressure, and cooling time before optimizing the minimum warpage. The ANOVA results 33.7, 21.6, 20.5, 16.1, 5.1, 1.5 and $1.3 \%$, respectively, to packing pressure, mould temperature, melt temperature, packing time, cooling time, runner type and gate location influence warpage. ANN created a predictive model for warpage and unites with GA for optimum process parameter value. For GA, the maximum warpage on the model before optimisation is $1.703 \mathrm{~mm}$ reduced to $0.819 \mathrm{~mm}$ when considering maximum warpage. The warpage reduced by $51 \%$ after optimisation.

Changyu et al. [12] studied the possibility of the modelling as well as estimating the injection moulded parts quality and improving the process conditions in order to enhance the part quality by using the combining ANN and GA method. A top cover of an industrial refrigerator was moulded by ABS material. At first, the Computer Aided Engineering (CAE) analysis was applied to find the range of each variable. Then, a model of Back Propagation (BP) neural network was used to design the complex nonlinear relationship between quality indexes and process conditions of the injection moulded parts. Based on ANN model, a GA was used in the process conditions optimisation with the fitness function. The combination of the ANN / GA method then was used in the process optimisation for the part model in order to enhance the quality index of part's volumetric shrinkage variation. As the result, ANN gives 0.487 of volumetric shrinkage, lower than all the test sample and train sample. 
There are some researchers used multi objective optimisation methods in order to reduce the defect in producing quality parts. In the injection moulding process, the multi objective optimization is used occasionally. Using a set of same input parameter, the multi objective method may help optimising more than one output like warpage and shrinkage [13].

Hakimian and Sulong [14] studied on reducing warpage and shrinkage using three different materials which were amorphous PC/ABS blend, amorphous Polyphenylene Ether/Polystyrene (PPE/PS), and crystalline Polyoxymethylene (POM) filled with glass fibres. A micro gear with $5.5 \mathrm{~mm}$ overall length, 18 gear teeth and $0.6 \mathrm{~mm}$ thickness was simulated using Autodesk MoldFlow with PC/ABS, PPE/PS and POM material. The parameter which is the cooling moulding temperature, melting temperatures, temperature, packing pressure, packing time, injection pressures, and fibreglass percentages were assigned as an important factor. Three interactions factor from those important factors were investigated. The injection parameters' effects on warpage and shrinkage at different fibreglass percentages and cooling temperatures were analysed according to the Taguchi method. As the result, the PC/ABS and PPE/PS composites had $0.0051 \mathrm{~mm}$ of minimum warpage and shrinkage was $2.2886 \%$, respectively.

In this study, the Genetic Algorithm (GA) is used as the optimisation method for minimising shrinkage with the help of Research Surface Methodology (RSM) for building up a mathematical model.

\section{Methodology}

\subsection{Simulation through Autodesk Moldflow Insight 2012}

Thick plate part, $4 \mathrm{~mm}$ thickness with single gate is chosen as a case study to minimise the shrinkage shown in Figure 1. The sprue, runner, and gate as well as the cooling channel are designed before the mould boundary is created. The thick plate part was moulded using ABS material produced by Polylac PA-777B manufactured by Chi Mei Corporation. The simulation of fill analysis, fill + pack analysis and cool analysis are simulated using Autodesk Moldflow Insight (AMI) 2012 to analyse the flow of material into mould cavities. The recommended results of AMI software are shown in Table 1. This result is used as before optimisation with shrinkage value in parallel and normal direction of $1.085 \mathrm{~mm}$ and $0.07 \mathrm{~mm}$, respectively.

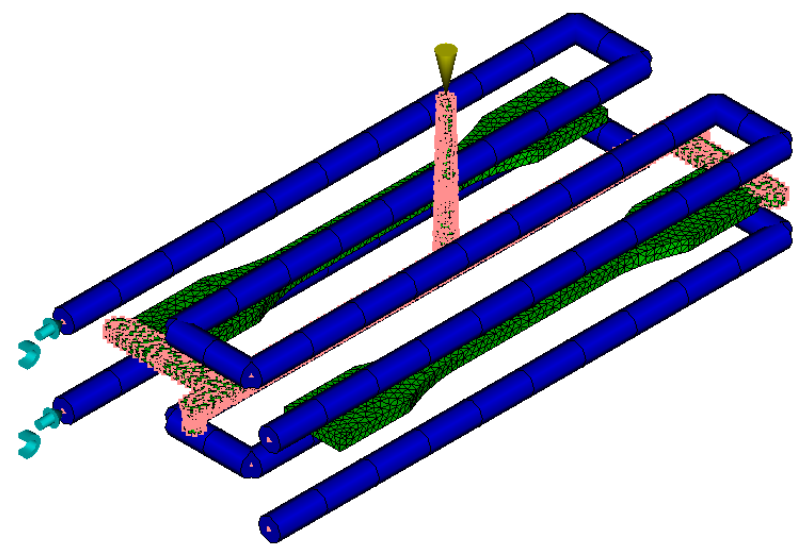

Fig. 1. Meshed model of thick plate part 
Table 1. Results recommend by Moldflow simulation

\begin{tabular}{|c|c|c|}
\hline \multicolumn{2}{|c|}{ Process Parameter } & Value \\
\hline \multicolumn{2}{|c|}{ Melt temperature $\left({ }^{\circ} \mathrm{C}\right)$} & 245 \\
\hline \multicolumn{2}{|c|}{ Mould temperature $\left({ }^{\circ} \mathrm{C}\right)$} & 65 \\
\hline \multirow{2}{*}{ Fill/ injection } & Time (s) & 2.75 \\
\hline & Velocity profile (mm) & 21 \\
\hline \multirow{2}{*}{ Packing } & Time (s) & 16 \\
\hline & Pressure (Mpa) & 50 \\
\hline \multicolumn{2}{|c|}{ Velocity/Pressure (V/P) switch over $(\mathrm{mm})$} & 21 \\
\hline \multicolumn{2}{|l|}{ Cooling time (s) } & 15.7 \\
\hline \multicolumn{2}{|c|}{ Coolant inlet temperature $\left({ }^{\circ} \mathrm{C}\right)$} & 50 \\
\hline \multirow[t]{2}{*}{ Shrinkage $(\mathrm{mm})$} & Parallel direction & 1.085 \\
\hline & Normal direction & 0.07 \\
\hline
\end{tabular}

Based on the previous researches, there are four factors that being chosen as the variable factors that influence the shrinkage in injection moulding which are the mould temperature (A), melt temperature (B), packing pressure (C) and packing time (D). Through this simulation, using the result obtained, the ranges of the factors were investigated before being used through cool (FEM) + fill + pack + warp analysis for identifying the shrinkage in $\mathrm{x}$ and $\mathrm{y}$ direction. The ranges of these factors are summarised in Table 2.

Table 2. Range of variable factors

\begin{tabular}{|c|c|}
\hline Variable Factors & Ranges \\
\hline Mould temperature $\left({ }^{\circ} \mathrm{C}\right)$ & $40-90$ \\
\hline Melt temperature $\left({ }^{\circ} \mathrm{C}\right)$ & $220-270$ \\
\hline Packing pressure $(\mathrm{MPa})$ & $30-70$ \\
\hline Packing time $(\mathrm{s})$ & $7.3-17.3$ \\
\hline
\end{tabular}

Through cool $($ FEM $)+$ fill + pack + warp analysis, four nodes of each two cavities are selected as the part where the shrinkage measurement is taken. The nodes, including the parallel (y) side and normal (x) side of the thick plate part like Figure 2 below. The parallel and normal nodes for cavity A are 4852, 3091 and 4339, 5245, respectively. Meanwhile, for cavity B, the parallel and normal nodes are 26031, 3385 and 25518, 26424, respectively. In cool $(\mathrm{FEM})+$ fill + pack + warp analysis, the value of mould temperature, melt temperature, packing pressure and packing time used are generated from the data of 30 levels of face-centered Central Composite Design (CCD) of Response Surface Methodology (RSM).

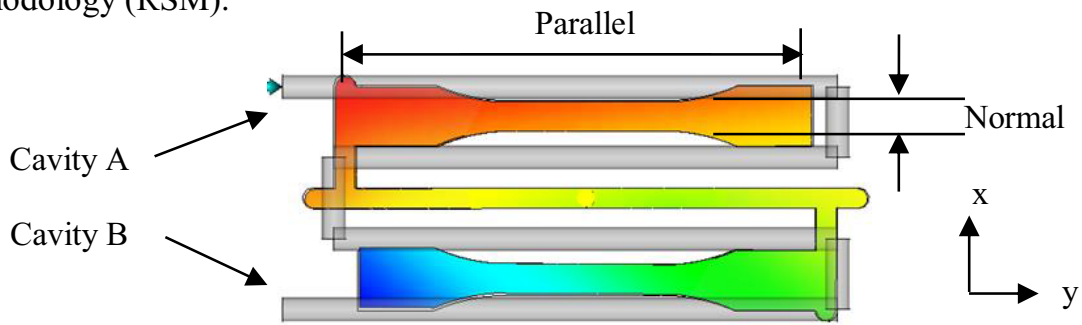

Fig. 2. Measurement method of shrinkage in parallel and normal direction 


\subsection{Simulation through Response Surface Methodology (RSM)}

RSM is one of the methods that widely used for prediction and optimisation [15-17]. In this study, before optimisation using the Genetic Algorithm (GA) method, the RSM used was to find out the mathematical model in parallel and normal direction. The CCD model with quadratic process order, backward and alpha, $\alpha$ equal to 0.05 augment the factorial design was used in RSM. There are 30 runs experiments generated by specified condition of facecentered CCD design can be seen in Table 3.

Table 3. Result of face-centered CCD design

\begin{tabular}{|c|c|c|c|c|c|c|}
\hline Run & $\mathbf{A}\left({ }^{\circ} \mathbf{C}\right)$ & $\mathbf{B}\left({ }^{\circ} \mathbf{C}\right)$ & $\begin{array}{c}\mathbf{C} \\
(\mathbf{M P a})\end{array}$ & $\mathbf{D}(\mathbf{s})$ & $\begin{array}{c}\text { Parallel } \\
(\mathbf{m m})\end{array}$ & $\begin{array}{c}\text { Normal } \\
(\mathbf{m m})\end{array}$ \\
\hline 1 & 90 & 270 & 30 & 17.3 & 1.365 & 0.090 \\
\hline 2 & 40 & 270 & 70 & 7.3 & 0.830 & 0.050 \\
\hline 3 & 65 & 245 & 50 & 12.3 & 1.120 & 0.070 \\
\hline 4 & 65 & 245 & 50 & 12.3 & 1.120 & 0.070 \\
\hline 5 & 90 & 270 & 70 & 17.3 & 1.020 & 0.060 \\
\hline 6 & 40 & 220 & 30 & 17.3 & 0.735 & 0.045 \\
\hline 7 & 90 & 270 & 30 & 7.3 & 1.370 & 0.090 \\
\hline 8 & 90 & 220 & 70 & 7.3 & 1.080 & 0.070 \\
\hline 9 & 40 & 270 & 70 & 17.3 & 0.850 & 0.050 \\
\hline 10 & 65 & 245 & 50 & 12.3 & 1.120 & 0.070 \\
\hline 11 & 90 & 270 & 70 & 7.3 & 0.970 & 0.060 \\
\hline 12 & 40 & 220 & 70 & 17.3 & 0.850 & 0.050 \\
\hline 13 & 90 & 220 & 70 & 17.3 & 0.970 & 0.060 \\
\hline 14 & 40 & 220 & 30 & 7.3 & 1.165 & 0.075 \\
\hline 15 & 90 & 220 & 30 & 7.3 & 1.255 & 0.080 \\
\hline 16 & 90 & 220 & 30 & 17.3 & 0.370 & 0.685 \\
\hline 17 & 40 & 220 & 70 & 7.3 & 0.845 & 0.055 \\
\hline 18 & 40 & 270 & 30 & 17.3 & 1.250 & 0.085 \\
\hline 19 & 40 & 270 & 30 & 7.3 & 1.270 & 0.090 \\
\hline 20 & 65 & 245 & 50 & 12.3 & 1.015 & 0.070 \\
\hline 21 & 65 & 245 & 30 & 12.3 & 1.160 & 0.080 \\
\hline 22 & 65 & 270 & 50 & 12.3 & 1.010 & 0.070 \\
\hline 23 & 65 & 245 & 50 & 17.3 & 1.115 & 0.070 \\
\hline 24 & 65 & 245 & 50 & 12.3 & 1.015 & 0.070 \\
\hline 25 & 65 & 245 & 50 & 7.3 & 0.975 & 0.070 \\
\hline 26 & 65 & 220 & 50 & 12.3 & 0.935 & 0.065 \\
\hline 27 & 65 & 245 & 70 & 12.3 & 0.810 & 0.060 \\
\hline 28 & 90 & 245 & 50 & 12.3 & 0.965 & 0.070 \\
\hline 29 & 40 & 245 & 50 & 12.3 & 1.025 & 0.070 \\
\hline 30 & 65 & 245 & 50 & 12.3 & 1.015 & 0.070 \\
\hline & & & & & & \\
\hline 10.350
\end{tabular}


All of the variable factors were established and represented as Equation 1 for shrinkage in parallel direction, $\mathrm{S}_{\text {parallel }}$ and Equation 2 for shrinkage in normal direction, $\mathrm{S}_{\text {normal }}$ of melt flow.

$$
\begin{aligned}
\mathrm{S}_{\text {parallel }} & =0.42568+6.11594 \mathrm{e}^{-0.003} \mathrm{~B}+0.040482 \mathrm{C}-0.23397 \mathrm{D} \\
& -2.25625 \mathrm{e}^{-0.004} \mathrm{BC}+7.32500 \mathrm{e}^{-0.004} \mathrm{BD}+8.15625 \mathrm{e}^{-0.004} \mathrm{CD} \\
& \mathrm{S}_{\text {normal }}{ }^{-1.53}=50.94176-0.48740 \mathrm{~A}+0.84762 \mathrm{C}
\end{aligned}
$$

where $\mathrm{A}$ is mould temperature $\left({ }^{\circ} \mathrm{C}\right), \mathrm{B}$ is melt temperature $\left({ }^{\circ} \mathrm{C}\right), \mathrm{C}$ is packing pressure $(\mathrm{MPa})$ and $\mathrm{D}$ is packing time (s).

\subsection{Simulation through Genetic Algorithm (GA)}

Genetic algorithms known as search algorithms built to imitate the exact principles of biological evolution under natural genetic system. GAs are also recognised as stochastic sampling techniques, and regularly used to solve difficult problems under the terms of objective functions that hold 'bad' properties, such as multi-modal, discontinuous, nondifferentiable and many more. These specific algorithms maintain and manipulate a population of solutions and implement their search for finer solutions based on 'survival of the fittest' strategy. GA solves linear and non-linear problems by considering all regions of the state space and utilizing encouraging areas through mutation, crossover, and selection process put in application to individuals in the population [18].

Using the range factor in Table 2, the value of each variable factor needs to encode into binary strings. This binary string is called as chromosomes. Each set of chromosomes constitutes a population and evolved during several generations or iteration. The chromosomes undergo the selection, based on the fitness, crossover and then the mutation for generating new generations (offspring).

Each solution given by fitness value and the higher fitness value gives chance for an individual to be selected in GA selection. Once the solution being selected, it will undergo the crossover. Crossover is the method that randomly selects one cut-point and to generate the offspring, the right parts of two parents are exchanged. In mutation, location is selected randomly and the bit number of a chromosome is flipped. Then, using a certain fitness criteria, the chromosomes are evaluated. The best ones are kept and the others are discharged. This process is repeated until a chromosome has the best fitness and it will be taken as the optimum solution.

The mathematical model generated from RSM technique is used through the GA method. The objective of this study is to minimise the shrinkage on the thick plate, put in both parallel and normal direction of melt flow. In this study, population size of 50, number of generations of 50, crossover rate of 0.40 , mutation rate of 0.01 , and bit number for each variable of 18 and 19 were employed.

\section{Results and Discussion}

After executing ANOVA, it was found that the packing pressure is the most significant factors that contribute shrinkage in both parallel and normal direction, followed by packing time, mould temperature and melt temperature. This result supported by Bushko and Stokes [19] which reported that the packing pressure resulting in minimising the shrinkage in both in-plane and through thickness direction. Ozcelik and Sonat [20] investigated that the most significant parameter for $\mathrm{PC} / \mathrm{ABS}$ material of cell thin shell phone cover is packing 
pressure. Subsequently, Huang and Tai [21] claimed that the packing pressure is the most influential factor that affects warpage after executing the ANOVA.

Figure 3 shows the variable factors result obtained through the evolution of generations for shrinkage in parallel direction of melt flow. The whole experimental design variable factors' are optimised by the basic coded GA by defining the population size to 50 . The optimised variable factors results are as following: the mould temperature is $79.45^{\circ} \mathrm{C}$, the melt temperature is $225.43{ }^{\circ} \mathrm{C}$, the packing pressure is $31.76 \mathrm{MPa}$, and the packing time is $17 \mathrm{~s}$ which summarised in Table 4 . The minimum shrinkage under the optimised variable factor conditions is $0.66127 \mathrm{~mm}$ based on Figure 4. The optimised shrinkage shows a reduction from the initial shrinkage before optimisation which at $1.085 \mathrm{~mm}$ based on Table 1. The shrinkage is improved by $39.1 \%$ after optimisation.

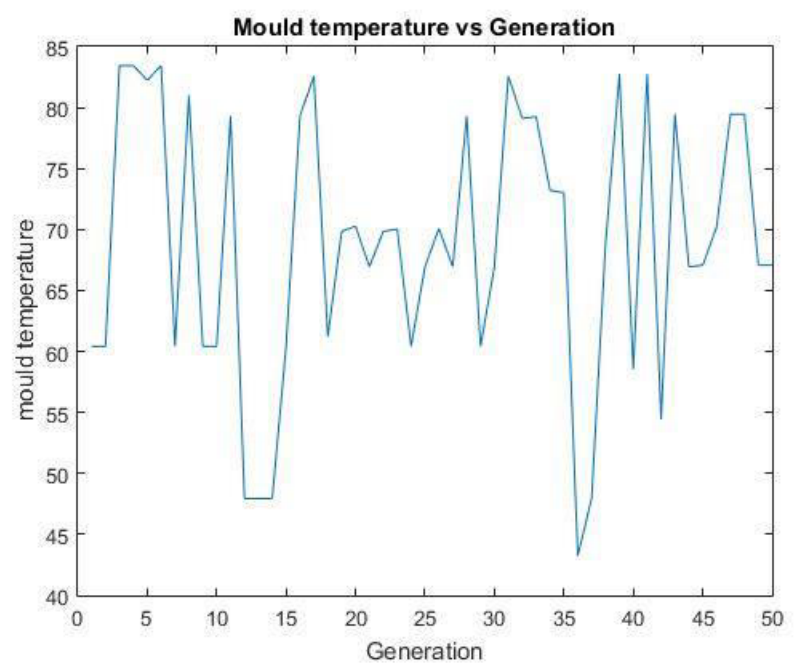

(a)

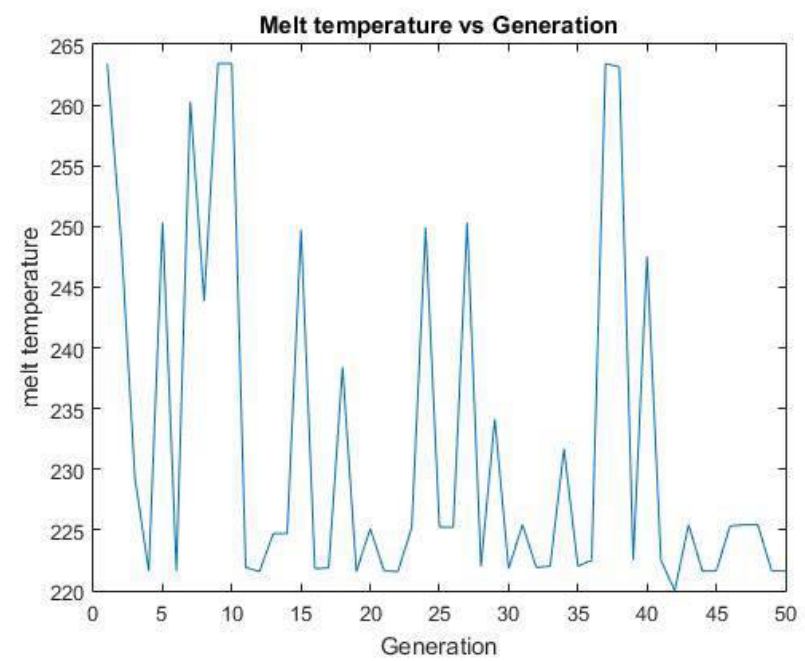

(b) 


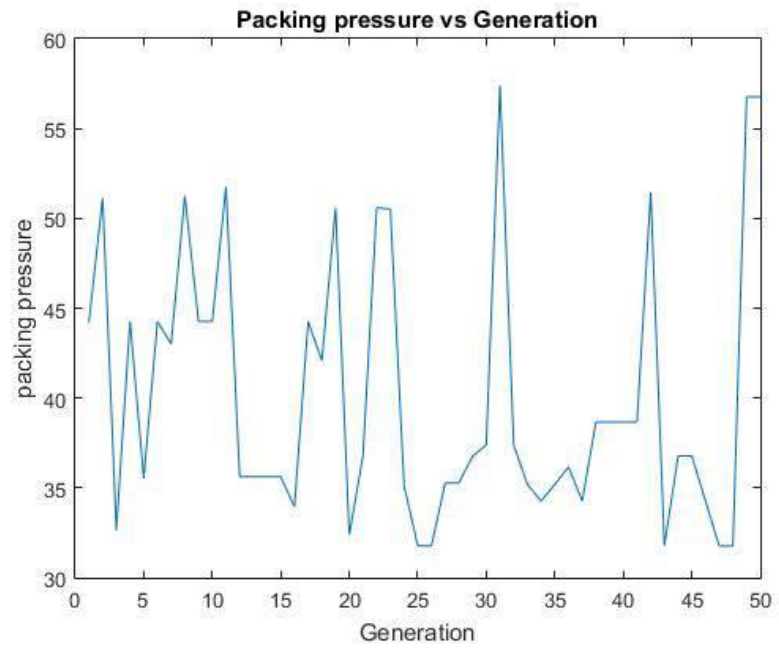

(c)

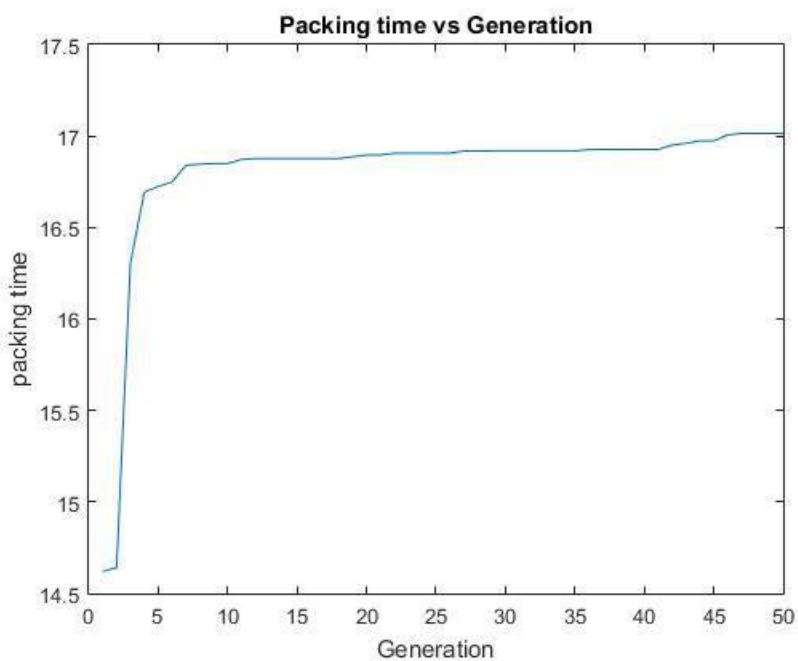

(d)

Fig. 3. (a) Mould temperature versus generation, (b) Melt temperature versus generation,(c) Packing pressure versus generation (d) Packing time versus generation 


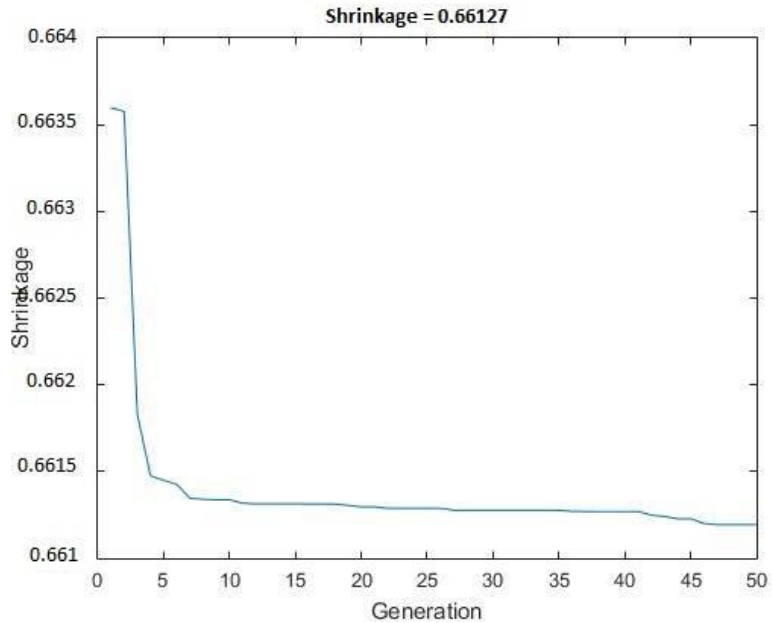

Fig. 4. Evolution of generations for the shrinkage defect

Table 4. Optimal values generated through GA method

\begin{tabular}{|l|c|}
\hline Variable Factor & After Optimisation \\
\hline Mould Temperature $\left({ }^{\circ} \mathrm{C}\right)$ & 79.45 \\
\hline Melt Temperature $\left({ }^{\circ} \mathrm{C}\right)$ & 225.43 \\
\hline Packing Pressure $(\mathrm{MPa})$ & 31.76 \\
\hline Packing Time $(\mathrm{s})$ & 17 \\
\hline Shrinkage $(\mathrm{mm})$ & 0.66127 \\
\hline
\end{tabular}

Meanwhile, for the shrinkage in normal direction, Figure 4 shows the variable factors result obtained through the evolution of generations. The whole experimental design variable factors' are optimised by real coded GA by defining the population size to 50 . The optimised variable factors results are as following: the mould temperature is $40.72^{\circ} \mathrm{C}$, the melt temperature is $231.8^{\circ} \mathrm{C}$, the packing pressure is $57.6 \mathrm{MPa}$, and the packing time is $17.3 \mathrm{~s}$ which summarised in Table 5. The minimum shrinkage under the optimised variable factor conditions is $0.057949 \mathrm{~mm}$ based on Figure 6. The optimised shrinkage shows a reduction from the initial shrinkage before optimisation which at $0.07 \mathrm{~mm}$ based on Table 1 . It can be concluded that the shrinkage is improved by $17.21 \%$ after optimisation.

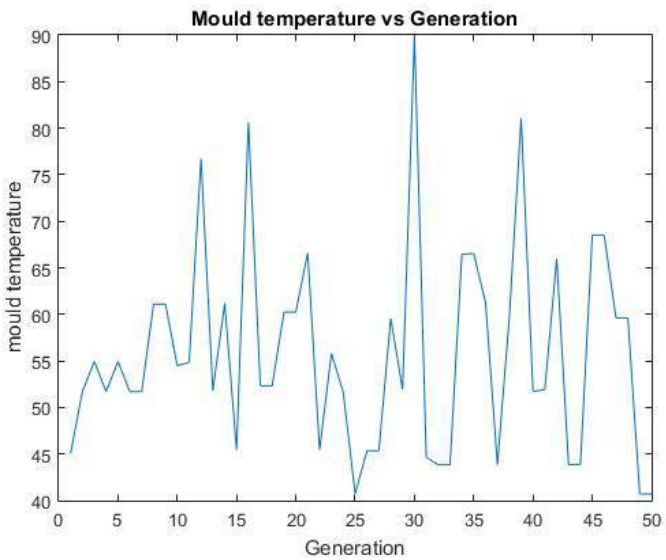

(a) 


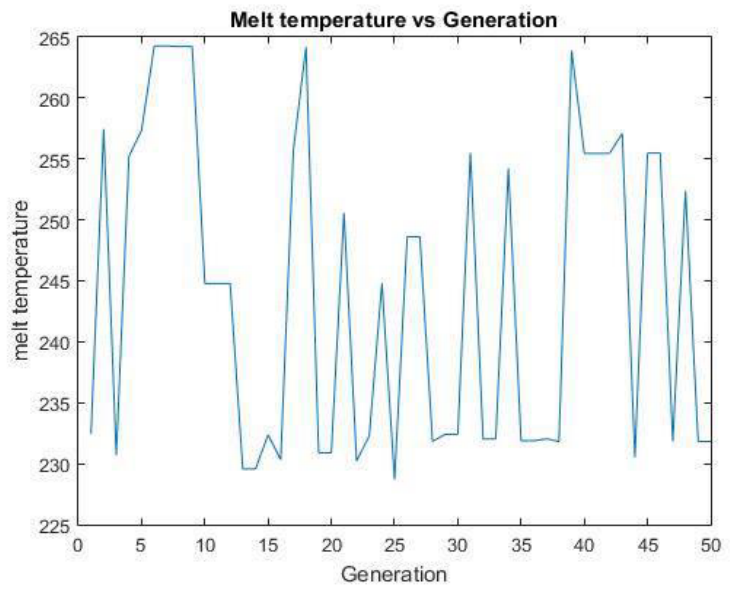

(b)

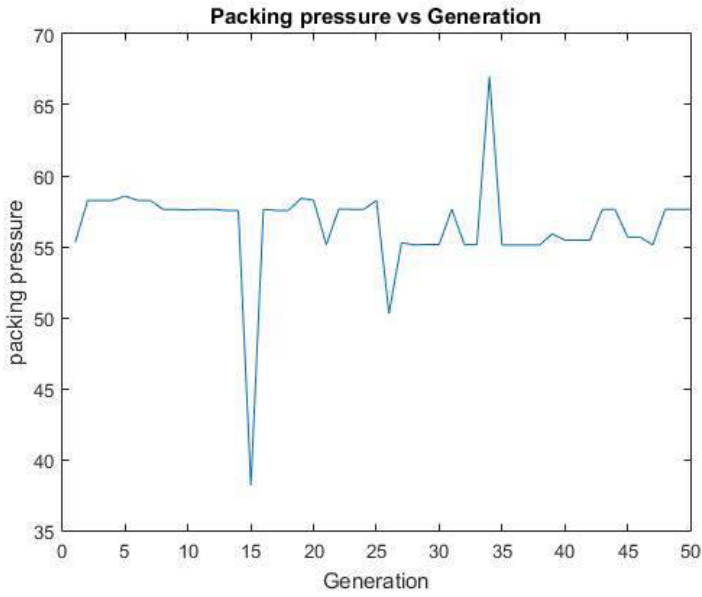

(c)

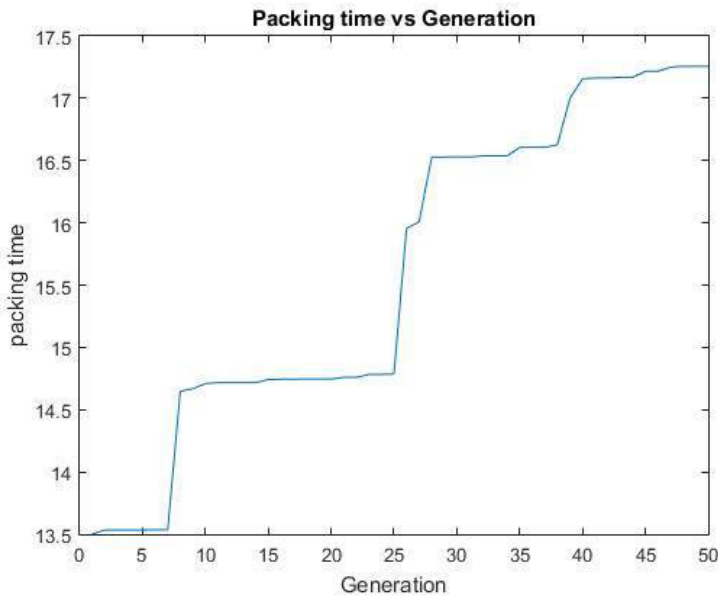

(d)

Fig. 5. (a) Mould temperature versus generation, (b) Melt temperature versus generation, (c) Packing pressure versus generation (d) Packing time versus generation 


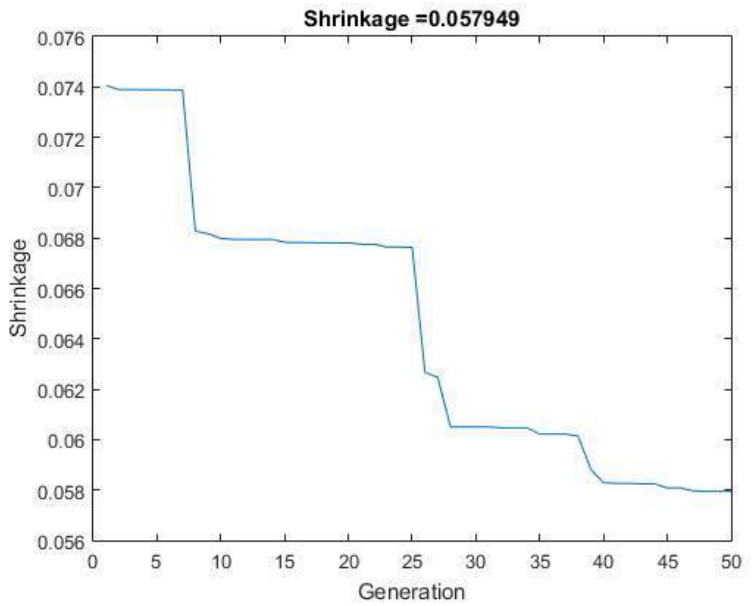

Fig. 6. Evolution of generations for the shrinkage defect

Table 5. Optimal values generated through GA method

\begin{tabular}{|l|c|}
\hline Variable Factor & After Optimisation \\
\hline Mould Temperature $\left({ }^{\circ} \mathrm{C}\right)$ & 40.72 \\
\hline Melt Temperature $\left({ }^{\circ} \mathrm{C}\right)$ & 231.8 \\
\hline Packing Pressure $(\mathrm{MPa})$ & 57.6 \\
\hline Packing Time $(\mathrm{s})$ & 17.3 \\
\hline Shrinkage $(\mathrm{mm})$ & 0.057949 \\
\hline
\end{tabular}

Based on Table 6, it can be shown that the variable factors for parallel and normal direction varies after optimisation. The value of shrinkage before optimisation for parallel and normal direction is taken from Table 1 which recommended by AMI software. Both shrinkage values in parallel and normal direction on the thick plate part is minimised through the GA method by $39.1 \%$ and $17.21 \%$, respectively.

Table 6. Comparison before and after optimisation

\begin{tabular}{|l|c|c|c|c|}
\hline \multirow{2}{*}{\multicolumn{1}{|c|}{ Parameters }} & \multicolumn{2}{c|}{ Before Optimisation } & \multicolumn{2}{c|}{ After Optimisation } \\
\cline { 2 - 5 } & Parallel & Normal & Parallel & Normal \\
\hline Mould Temperature $\left({ }^{\circ} \mathrm{C}\right)$ & 65 & 65 & 79.45 & 40.72 \\
\hline Melt Temperature $\left({ }^{\circ} \mathrm{C}\right)$ & 245 & 245 & 225.43 & 231.8 \\
\hline Packing Pressure $(\mathrm{MPa})$ & 50 & 50 & 31.76 & 57.6 \\
\hline Packing Time $(\mathrm{s})$ & 16 & 16 & 17 & 17.3 \\
\hline Shrinkage $(\mathrm{mm})$ & 1.085 & 0.070 & 0.66127 & 0.05795 \\
\hline
\end{tabular}

\section{Conclusion}

In this study, best injection moulding process conditions are determined to enable minimum shrinkage. In finding optimum values, power of Finite Element (FE) software Moldflow, and GA is exploited. GA is an appropriate method to obtain the global optimal solution of the complex non-linear problem. Mould temperature, melt temperature, packing pressure, and packing time are considered as process parameters. FE analyses are conducted in combination of variable factors designed using statistical CCD face-centered experiment design. The experimental design is integrated with an effective genetic algorithm to find the optimum process parameter values. GA optimisation reduces the minimum shrinkage for 
parallel and normal direction to $0.66127 \mathrm{~mm}$ and $0.057949 \mathrm{~mm}$, respectively. The findings in this study also indicate that packing pressure is the most significant factors. The optimisation methodology in this study can be employed to improve the shrinkage in the thick plate part.

\section{References}

1. S.H. Tang, Y.M. Kong, S.M. Sapuan, R. Samin, S. Sulaiman, J. Mater. Process. Technol., 171, 259 (2006)

2. S.S. Korke, Analysis and measurement of warpage for linear flow of amorphous and crystalline materials, (University of Massachusetts, Lowell, 1997)

3. P.P. Shinde, S.S. Patil, S.S. Kulkarni, International Journal of Advanced Engineering Research and Studies, (2014)

4. T. Samson, Simulation and Design of a plastic injection mold-A Joint mold for credit card and USB holder, (Arcada, Helsinki, 2011)

5. Y. Gao, X. Wang, Int. J. Adv. Manuf. Tech., 37, 953 (2008)

6. Z. Kamal, Trouble Shooting In Plastic Injection Molding Machines, (NJIT, New Jersey, 1993).

7. B. Ozcelik, Int. Commun. Heat. Mass., 38, 1067 (2011)

8. C.Y. Wu, C.C. Ku, H.Y. Pai, Int. J. Adv. Manuf. Tech., 52, 131 (2010)

9. F. Yin, H. Mao, L. Hua, Mater. Design, 32, 3457 (2011)

10. B. Ozcelik, T. Erzurumlu, Int. Commun. Heat. Mass., 32, 1085 (2005)

11. B. Ozcelik, T. Erzurumlu, J. Mater. Process. Technol., 171, 437 (2006)

12. C. Shen, L. Wang, Q. Li, J. Mater. Process. Technol., 183, 412 (2007)

13. S.M. Nasir, K.A. Ismail, Z. Shayfull, N.A. Shuaib, International Journal of Mechanical Engineering, 7, 977 (2013)

14. E. Hakimian, A. B. Sulong, Mater. Design, 42, 62 (2012)

15. N.N. Aimi, H. Anuar, M.R. Manshor, W.B.W. Nazri, S.M. Sapuan, Ind. Crop. Prod., 54, 291 (2014)

16. G. Chi, S. Hu, Y. Yang, T. Chen, Chem. Eng. Res. Des., 90, 1235 (2012)

17. A.M. Zain, H. Haron, S. Sharif, Expert. Syst. Appl., 37, 4650 (2010)

18. R.H. Christopher, A.J. Jeffery, G.K. Michael, A Genetic Algorithm for function optimization: a MATLAB implementation (NSCU, Raleigh, 1995)

19. W.C. Bushko, V.K. Stokes, Polym. Eng. Sci., 35, 365 (1995)

20. B. Ozcelik, I. Sonat, Mater. Design, 30, 367 (2009)

21. M.C. Huang, C.C. Tai, J. Mater. Process. Technol., 110, 1 (2001) 